\title{
Condensational uptake of semivolatile organic compounds in gasoline engine exhaust onto pre-existing inorganic particles
}

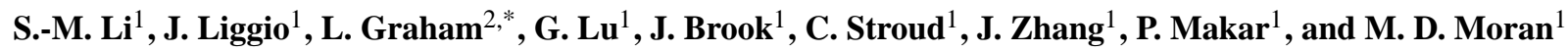 \\ ${ }^{1}$ Air Quality Research Division, Atmospheric Science and Technology Directorate, Science and Technology Branch, \\ Environment Canada, 4905 Dufferin Street, Toronto, Ontario, M3H 5T4, Canada \\ ${ }^{2}$ Air Quality Research Division, Atmospheric Science and Technology Directorate, Science and Technology Branch, \\ Environment Canada, 335 River Road, Ottawa, Ontario, K1A 0H3, Canada \\ *now at: Department of Chemistry, University of Christchurch, Canterbury 8041, New Zealand
}

Received: 29 November 2010 - Published in Atmos. Chem. Phys. Discuss.: 31 January 2011

Revised: 13 August 2011 - Accepted: 14 September 2011 - Published: 10 October 2011

\begin{abstract}
This paper presents the results of laboratory studies on the condensational uptake of gaseous organic compounds in the exhaust of a light-duty gasoline engine onto preexisting sulfate and nitrate seed particles. Significant condensation of the gaseous organic compounds in the exhaust occurs onto these inorganic particles on a time scale of 2$5 \mathrm{~min}$. The amount of condensed organic mass (COM) is proportional to the seed particle mass, suggesting that the uptake is due to dissolution determined by the equilibrium partitioning between gas phase and particles, not adsorption. The amount of dissolution in unit seed mass, $S$, decreases as a power function with increased dilution of the exhaust, ranging from $0.23 \mathrm{~g} \mathrm{~g}^{-1}$ at a dilution ratio of 81 , to $0.025 \mathrm{~g} \mathrm{~g}^{-1}$ at a dilution ratio of 2230 . It increases nonlinearly with increasing concentration of the total hydrocarbons in the gas phase (THC), rising from $0.12 \mathrm{~g} \mathrm{~g}^{-1}$ to $0.26 \mathrm{~g} \mathrm{~g}^{-1}$ for a $C_{\mathrm{THC}}$ increase of 1 to $18 \mu \mathrm{g} \mathrm{m}^{-3}$, suggesting that more organics are partitioned into the particles at higher gas phase concentrations. In terms of gas-particle partitioning, the condensational uptake of THC gases in gasoline engine exhaust can account for up to $30 \%$ of the total gas + particle THC. The organic mass spectrum of COM has the largest fragment at $\mathrm{m} / \mathrm{z} 44$, with mass ratios of mass fragments $43 / 44$ and 57/44 at 0.59 and 2.91 , much lower than those reported for gasoline engine primary organic aerosols. The mass fragment 44/total organic mass ratio of 0.097 indicates that COM contains large oxygenated components. By incorporating the present findings, regional air quality modelling results sug-
\end{abstract}

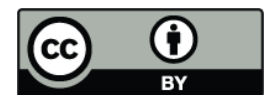

Correspondence to: $\mathrm{S} . \mathrm{M}$. Li

(shao-meng.li@ec.gc.ca) gest that the condensational uptake of THC onto sulfate particles alone can be comparable to the primary particle mass under moderately polluted ambient conditions. These findings are important for modelling and regulating the air quality impacts of gasoline vehicular emissions.

\section{Introduction}

Airborne particles are known to pose serious health risks (Dockery et al., 1993; Geller et al., 2006; Schwarze et al., 2006; Pope and Dockery, 2006; Brook et al., 2010) and have a large influence on the Earth's climate (Jacob and Winner, 2009). Such impacts are increasing public and government scrutiny of particulate matter (PM) emissions from all anthropogenic activities. Primary PM from automotive engine exhaust is among the most studied and regulated emissions over recent decades; yet to conform with current regulations, automotive emissions of primary particles are determined on a mass basis which ignore complex at-source processes that re-distribute the semivolatile organic compounds (SVOCs) between gas and particle phases. Standard automotive PM mass emission measurements, based on sampling on filters and gravimetric analysis, have proven to be artifact-prone, particularly at low emissions levels (Chase et al., 2004; Lipsky and Robinson, 2006). Determining PM levels in emissions at dilution levels spanning several orders of magnitude can be a significant challenge, affected by even the slightest details in the vehicle testing and sampling protocols. Direct particle size distribution measurements are now a recommended method to characterize particle emission from engine exhaust, particularly with the recent focus on the particle

Published by Copernicus Publications on behalf of the European Geosciences Union. 
number concentrations in newer standards, such as EURO 5 and 6 (European Commission, 2008).

The most difficult measurement challenge arises from the highly dynamic situations of cooling and dilution upon mixing with the ambient atmosphere, where the steady-state equilibrium between gases and particles in the exhaust is easily shifted. This can lead to changes in the physical and chemical characteristics of particles. Notable recent studies have focused on the impacts of ambient temperature and dilution on PM emissions (Lipsky and Robinson, 2006; Grieshop et al., 2009) and low ambient temperature is known to result in the enhanced formation of nucleation mode particles in gasoline and diesel vehicle exhaust (Mathis et al., 2004, 2005). Robinson et al. (2007) demonstrated that upon dilution, diesel exhaust PM mass decreases due to evaporative loss of SVOCs from the particles. Shrivastava et al. (2006) considered the impact of background organic aerosols on the partitioning of emissions from diesel and wood combustion, and found that partitioning to particles is enhanced by higher background organic aerosols concentrations. Gasoline engine particulate emissions are less well studied and it is difficult to predict whether primary particles in gasoline engine exhaust behave similarly to diesel particles upon dilution and mixing with ambient air, given the large differences in the exhaust compositions of gasoline engines and diesel engines.

What has not been considered in the automotive primary $\mathrm{PM}$ emission studies to date is the condensational uptake of gaseous pollutants to pre-existing ambient inorganic particles upon the initial mixing of engine exhaust with ambient air. Theories of gas-particle partitioning dictate that at least some of the SVOCs in exhaust gases, particularly the polar compounds, will condense and reach equilibrium with ambient particles of inorganic composition under atmospheric conditions. There is circumstantial evidence pointing to this re-partitioning within exhaust gases (Kittelson, 1998; Khalek et al., 1999; Maricq et al., 1999; Mathis et al., 2004; Lipsky and Robinson, 2006). For example, diesel primary particles are known to contain solid cores of soot with adsorbed hydrocarbons, nitrates and sulfates (Sakurai et al., 2003; Kwon et al., 2003), and there is evidence that the growth of the nucleation mode particles is partially attributable to condensation (Mathis et al., 2004). The adsorbed hydrocarbons are in dynamic equilibrium with the gas phase, moving in and out of the primary particles as temperature and concentration change. Such processes should also occur once the gaseous exhaust comes into contact with ambient particles that provide surface area or volume for uptake to occur, but few studies have reported on the uptake process onto ambient particles, and it is not known how significant this process is in terms of release of primary PM into the ambient atmosphere. Although this uptake takes place in the atmosphere after the exhaust is emitted, the time and spatial scales associated with mixing and dilution at the tailpipe and uptake of gases on ambient particles are from seconds to minutes and from tens to hundreds of meters. Hence, from the standpoint of health impacts and for atmospheric models, the condensed SVOC species will be difficult to distinguish from primary PM mass.

The present study addresses the condensational uptake of organic gaseous pollutants on ambient particles. PM emissions studies focused on gasoline engine exhaust are relatively few compared to those on diesel exhaust, since exhaust PM levels of modern catalyst-equipped, properly-operating gasoline engines are low. In this study, the magnitude of the condensational uptake of organic materials in gasoline engine emissions is quantified, and a parameterization of the condensational uptake onto pre-existing particles is derived. This parameterization is further used in a regional air quality model to assess the impact of this process on a regional basis.

\section{Experimental design}

The experiments were carried out using the setup illustrated in Fig. 1. This setup consisted of two sections, an engine testing facility from which the primary PM measurements were made, and a flow tube where the gas uptake and condensation on pre-existing particles was investigated.

\subsection{Gas and primary particle emissions measurements}

In the engine testing facility, a multi-port injected gasoline engine, recovered from a 1991 model year General Motors Lumina light duty vehicle, was equipped with a new but degreened original equipment three-way catalyst. The engine was installed on a dynamometer and enclosed in a controlledaccess test room. The engine exhaust was directly vented into a constant volume sampling (CVS) system, where it underwent primary dilution with a dilution ratio between 14-22 (Table 1), and was kept at an ambient temperature of $25^{\circ} \mathrm{C}$.

Concentrations of $\mathrm{CO}, \mathrm{CO}_{2}, \mathrm{NO}_{\mathrm{x}}$ and total hydrocarbon (THC) in the primary dilute exhaust in the CVS were monitored using non-dispersive infrared analyzers for $\mathrm{CO}$ and $\mathrm{CO}_{2}$, chemiluminescence analyzers for $\mathrm{NO}_{\mathrm{x}}\left(\mathrm{NO}+\mathrm{NO}_{2}\right)$, and a flame ionization detector for THC. The analyzers were zeroed and spanned to adjust for instrument drift every $30 \mathrm{~min}$. The flame ionization detector was calibrated with propane and concentration of THC was reported in ppm carbon (ppmC).

Primary particles in the CVS were characterized with a scanning mobility particle spectrometer (SMPS, TSI model 3080) using a differential mobility analyzer (nano-DMA) column (TSI model 3085) and a TSI model 3025A condensation particle counter (CPC) for sizing particles from 4.6 to $162.5 \mathrm{~nm}$ diameter. The SMPS scanned over the size range on a 3-min scanning cycle. A second CPC (TSI model 3022A) was used to monitor the particle number concentrations, for particles as small as $7 \mathrm{~nm}$. The second CPC monitored secondary dilute exhaust after second-stage dilution using Dekati ejection diluters, either one or two in 


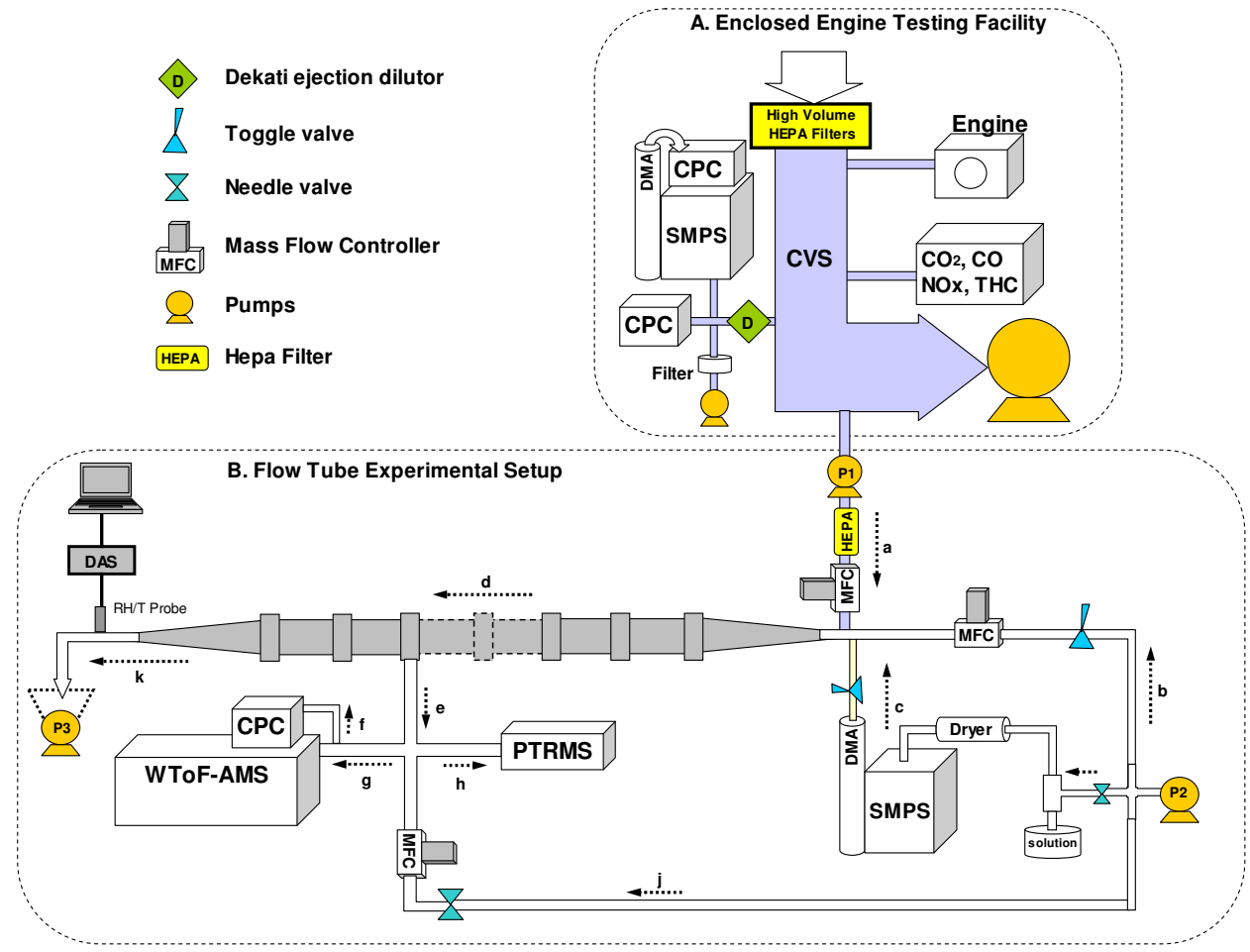

Fig. 1. An illustration of the experimental setup for this study. Section A shows the setup of the engine testing facility, where measurements of primary particles in the primary diluted exhaust in the CVS are made using SMPS, CPC, and filters. A small flow from the primary dilute exhaust in the CVS is pumped into the flow tubes, where it is mixed with laboratory generated seed particles. Arrows in Section B show the streams of air flow in the setup.

Table 1. Engine Operating Conditions and Gas and Primary Particle Characteristics in the Constant Volume Sampler (CVS).

\begin{tabular}{|c|c|c|c|c|c|c|c|c|c|c|c|c|c|}
\hline \multirow[t]{2}{*}{$\begin{array}{l}\text { Test Date } \\
(2007)\end{array}$} & \multirow[t]{2}{*}{ Engine Mode ${ }^{a}$} & \multirow{2}{*}{$\begin{array}{c}\begin{array}{c}\text { Duration of } \\
\text { Experiments }\end{array} \\
(\min )\end{array}$} & \multirow{2}{*}{$\begin{array}{c}\begin{array}{c}\text { Primary } \\
\text { Dilution Ratio }\end{array} \\
\mathrm{F}_{\text {cvs }} / \mathrm{F}_{\text {exhaust }}\end{array}$} & \multicolumn{3}{|c|}{$\begin{array}{l}\text { Average Gas Phase } \\
\text { Concentrations in CVS }\end{array}$} & \multicolumn{7}{|c|}{$\begin{array}{c}\text { Primary Particle Mass and Number Size Distribution Characteristics in Primary } \\
\text { Dilute Exhaust }\end{array}$} \\
\hline & & & & $\begin{array}{l}\mathrm{CO}_{2} \\
(\%)\end{array}$ & $\begin{array}{l}\mathrm{NO}_{\mathrm{x}} \\
(\mathrm{ppm})\end{array}$ & $\begin{array}{c}\mathrm{THC} \\
(\mathrm{ppmC})\end{array}$ & $\begin{array}{c}\text { Total } \\
\text { Mass } \\
\left(\mu \mathrm{g} \mathrm{m}^{-3}\right)^{\mathrm{c}}\end{array}$ & $\begin{array}{c}\text { Total } \\
\text { Number } \\
\text { (/cc) }\end{array}$ & $\begin{array}{c}\text { Median } \\
(\mathrm{nm})\end{array}$ & $\begin{array}{c}\text { Mean } \\
(\mathrm{nm})\end{array}$ & $\begin{array}{c}\text { Mode } \\
(\mathrm{nm})\end{array}$ & $\begin{array}{l}\text { Geo. Mean } \\
\quad(\mathrm{nm})\end{array}$ & Geo. Std Dev \\
\hline $19 \mathrm{Apr}$ & 3 & 460 & 16.8 & 0.80 & 67.5 & 5.61 & $\mathrm{n} / \mathrm{a}$ & $3.61 \mathrm{E} \times 10^{7}$ & $9.0 \pm 1.7$ & $9.2 \pm 1.7$ & $8.8 \pm 1.9$ & $9.0 \pm 1.6$ & $1.1-1.4$ \\
\hline $20 \mathrm{Apr}^{\mathrm{b}}$ & 3 & 300 & 16.5 & 0.81 & 61.1 & 5.49 & $\mathrm{n} / \mathrm{a}$ & $\mathrm{n} / \mathrm{a}$ & $\mathrm{n} / \mathrm{a}$ & $\mathrm{n} / \mathrm{a}$ & $\mathrm{n} / \mathrm{a}$ & $\mathrm{n} / \mathrm{a}$ & $\mathrm{n} / \mathrm{a}$ \\
\hline \multirow[t]{2}{*}{$24 \mathrm{Apr}$} & 1 & 120 & 14.2 & 0.94 & 173 & 6.16 & $740 \pm 630$ & $1.91 \times 10^{8}$ & $13.6 \pm 3.6$ & $14.1 \pm 3.6$ & $14.2 \pm 4.6$ & $13.2 \pm 3.2$ & $1.3-1.5$ \\
\hline & 1 & 100 & 14.1 & 0.95 & 154 & 6.15 & $110 \pm 710$ & $3.94 \times 10^{8}$ & $12.6 \pm 2.0$ & $12.9 \pm 2.0$ & $13.2 \pm 2.6$ & $12.2 \pm 1.8$ & $1.2-1.5$ \\
\hline $25 \mathrm{Apr}$ & 2 & 400 & 22.3 & 0.60 & 68.3 & 6.68 & $220 \pm 140$ & $2.09 \times 10^{8}$ & $6.9 \pm 1.1$ & $7.3 \pm 1.1$ & $6.5 \pm 1.8$ & $7.0 \pm 1.0$ & $1.2-1.4$ \\
\hline \multirow[t]{2}{*}{$26 \mathrm{Apr}$} & 1 & 350 & 14.2 & 0.94 & 180 & 5.75 & $1350 \pm 370$ & $4.81 \times 10^{8}$ & $13.5 \pm 0.9$ & $13.8 \pm 0.9$ & $14.9 \pm 1.5$ & $12.9 \pm 0.8$ & $1.4-1.5$ \\
\hline & 1 & 90 & 14.2 & 0.94 & 180 & 6.22 & $2000 \pm 160$ & $5.18 \times 10^{8}$ & $15.0 \pm 0.9$ & $15.3 \pm 0.8$ & $16.5 \pm 1.2$ & $14.2 \pm 0.7$ & $1.4-1.5$ \\
\hline $27 \mathrm{Apr}$ & 3 & 290 & 16.8 & 0.80 & 57.6 & 6.09 & $850 \pm 400$ & $4.65 \times 10^{8}$ & $10.8 \pm 2.4$ & $11.1 \pm 2.3$ & $11.5 \pm 3.1$ & $10.5 \pm 2.1$ & $1.3-1.5$ \\
\hline \multirow[t]{2}{*}{1 May } & 2 & 270 & 22.3 & 0.60 & 67.1 & 5.57 & $550 \pm 410$ & $3.63 \times 10^{8}$ & $10.1 \pm 2.4$ & $10.5 \pm 2.3$ & $10.5 \pm 3.1$ & $9.9 \pm 2.0$ & $1.3-1.5$ \\
\hline & 2 & 130 & 22.3 & 0.60 & 67.1 & 5.80 & $1260 \pm 210$ & $4.93 \times 10^{8}$ & $12.9 \pm 0.9$ & $13.3 \pm 0.8$ & $14.1 \pm 1.3$ & $12.4 \pm 0.7$ & $1.4-1.5$ \\
\hline \multirow[t]{2}{*}{2 May } & 1 & 270 & 14.1 & 0.95 & 183 & 6.15 & $1930 \pm 170$ & $4.55 \times 10^{8}$ & $15.9 \pm 0.6$ & $16.2 \pm 0.6$ & $16.9 \pm 1.0$ & $15.3 \pm 0.5$ & $1.4-1.5$ \\
\hline & 1 & 110 & 14.2 & 0.94 & 182 & 6.14 & $2150 \pm 110$ & $5.07 \times 10^{8}$ & $15.9 \pm 0.6$ & $16.1 \pm 0.6$ & $17.0 \pm 1.1$ & $15.2 \pm 0.5$ & $1.4-1.5$ \\
\hline
\end{tabular}

${ }^{a}$ Mode 1: engine speed 1700 RPM, engine torque $73 \mathrm{ft}-\mathrm{lb}$; Mode 2: engine speed $1700 \mathrm{RPM}$, engine torque $47 \mathrm{ft}-\mathrm{lb}$; Mode 3 : engine speed $2250 \mathrm{RPM}$, engine torque $47 \mathrm{ft}-\mathrm{lb}$. All experiments were conducted after the engine has warmed up from a cold start.

b Particles in the primary dilute exhaust were not measured on 20 April 2007.

${ }^{\mathrm{c}}$ Total mass and number of the primary particles are derived from SMPS number size distributions after the SMPS reached steady-state, assuming a density of $1.4 \mathrm{~g}$ cm ${ }^{-3}$ (Larson et al., 1988; Park et al., 2003). The SMPS did not reach a steady-state on 20 April . 
series. The single diluter achieved a 7:1 dilution from the primary dilute exhaust in the CVS, and two in series achieved a 56:1 dilution.

\subsection{Engine operation mode}

During the experiments, the engine was operated in three modes of engine speed (namely, rotation per minute or RPM) and load that simulate different driving conditions (Table 1). The engine was operated continuously for several hours in each mode that was necessary for the condensational uptake experiments. For the experiments, the engine was operated on Canadian commercial summer grade gasoline with sulphur content $<30 \mathrm{ppm}$. The CVS system was operated at a fixed total volume flow rate $\left(F_{\mathrm{CVS}}\right)$ of $21.24 \mathrm{~m}^{3} \mathrm{~min}^{-1}$. Thus, depending on the RPM, the primary dilution ratio, defined as $F_{\mathrm{CVS}} / \mathrm{F}_{\text {exhaust }}$, varied over a range of 14.1 to 22.3 (Table 1). Concentrations of $\mathrm{CO}, \mathrm{CO}_{2}, \mathrm{NO}_{\mathrm{x}}$ and THC in the primary dilute exhaust in the CVS were monitored every second in repeated 30-min segments.

\subsection{Condensational uptake experimental setup}

The flow tube setup, depicted in Section B of Fig. 1, was designed to measure the condensational uptake of gases on particles. In these studies, laboratory-generated seed particles were used as surrogates for ambient inorganic particles. The flow tubes were Teflon-coated stainless steel tubes of $2.54 \mathrm{~cm}$ inner diameter and $30 \mathrm{~cm}$ length. A total of 13 tubes were connected together using connectors equipped with sampling ports. Three air streams were delivered into the flow tubes (streams a, b, and c, Fig. 1), one carrying the primary gas exhaust (stream a), one carrying zero air for dilution (stream b), and one carrying seed particles (stream c). At the end of the flow tubes, a probe was used to measure the relative humidity (RH) and temperature of the mixture in the flow tubes.

Seed particles were generated by atomizing a solution of $\mathrm{H}_{2} \mathrm{SO}_{4} /\left(\mathrm{NH}_{4}\right)_{2} \mathrm{SO}_{4}$ with a constant volume atomizer (TSI model 3076) with compressed zero air generated from a zero air source (AADCO model 737). Depending on the experiment, the ratio of $\mathrm{H}_{2} \mathrm{SO}_{4}$ to $\left(\mathrm{NH}_{4}\right)_{2} \mathrm{SO}_{4}$ in the solution was chosen to give different initial particle acidities; however, in most experiments the sampled particles were neutral after exposure to $\mathrm{NH}_{3}$ in the engine exhaust in the flow tube. In a few experiments, $\mathrm{NH}_{4} \mathrm{NO}_{3}$ particles were generated instead of sulfate particles. These particles were dried using a diffusion dryer (TSI model 3062), and size selected using a TSI SMPS/DMA model 3080/3081 before being delivered into the flow tubes.

The seed particles were introduced into the first flow tube at its central axis through $1 / 4$ inch outer diameter (o.d.) stainless steel tubing. This was designed with a coaxial introduction of the primary dilute exhaust gas. The dilute exhaust was pumped from the CVS using a Teflon diaphragm pump through a HEPA filter to remove the primary particles (stream a). This particle-free exhaust gas was introduced into the first flow tube through a $1 / 8$ inch o.d. stainless steel tube that is nested at the centre of the $1 / 4$ inch line used to introduce the particles. Entry linear velocities of both the seed particle flow and the exhaust gas flow into the flow tube were maintained to be the same in some experiments, although it was found that the effect of initial linear velocities of either the particles or the exhaust gases on organic condensation on the particles was minimal. Thus, both the particles and the dilute exhaust gas traveled down the flow tubes concentrically along the axis of the flow tubes. The mixing of the exhaust gas and the seed particle flows from their introduction at the first flow tube constituted a secondary dilution, with a dilution ratio determined by the flow rates from both flow streams a and c in Fig. 1. In a few experiments, extra dilution was made with an additional flow stream of zero air (flow stream b in Fig. 1).

Sampling of particles was made at the central axial position in the air stream flowing down the flow tubes through a $1 / 4$ inch stainless steel tube inserted radially through selected sampling ports. Depending on the experiment, a tertiary dilution was made at the $1 / 4$ inch sampling port that also helped to balance the flows. After the tertiary dilution, the 1/4 inch stainless steel sampling line was split and fed to three instruments, an aerosol mass spectrometer (AMS), a CPC (TSI model 3775), and a proton transfer reaction mass spectrometer (PTRMS). The contact time between the seed particles and the diluted exhaust varied from 1.5 to $7 \mathrm{~min}$, depending on the total flow rate through the flow tubes and the position of the sampling port, as further discussed below. Residence time in the sampling line was approximately 1 second.

The particle chemical composition and mass were monitored using an Aerodyne Research Inc high resolution timeof-flight aerosol mass spectrometer (HR-ToF-AMS; DeCarlo et al., 2006). The HR-ToF-AMS was operated in the high sensitivity mode (V-mode) with a 2-min time resolution. Particle sulfate, nitrate and ammonium size distributions were monitored using the particle time-of-flight mode of the HRToF-AMS. The AMS data was analyzed using a fragmentation table with modifications as suggested by Aiken et al. (2009). The $m / z 44$ signal was also corrected for $\mathrm{CO}_{2}$ in the background.

\subsection{Uptake and condensation conditions}

Experimental conditions were designed to target each of five controlling factors on the uptake and condensation, including relative humidity, duration of exposure, chemical composition, seed particle sizes and dilution ratios. Table 2 shows the range of the factors that were varied to determine the impacts of these factors. During all experiments, temperature in the air flow inside the flow tube varied in a narrow range of $23.5-28.8^{\circ} \mathrm{C}$, whereas the $\mathrm{RH}$ changed from $6.5 \%$ 
Table 2. Uptake and condensation control parameter range during the study.

\begin{tabular}{lccccc}
\hline Date & $\begin{array}{c}\text { Number of } \\
\text { Experiments }\end{array}$ & $\begin{array}{c}\text { Relative } \\
\text { Humidity* }\end{array}$ & $\begin{array}{c}\text { Exposure } \\
\text { Time (min) }\end{array}$ & $\begin{array}{c}\text { Seed Particle } \\
\text { Size (nm) }\end{array}$ & $\begin{array}{c}\text { Final Dilution } \\
\text { Ratio }\end{array}$ \\
\hline $19 \mathrm{Apr}$ & 15 & $6.5-11.2$ & $2.14-8.30$ & 300 & $235-504$ \\
$20 \mathrm{Apr}$ & 11 & $7.2-20.1$ & 5.52 & 300 & 83 \\
$24 \mathrm{Apr}$ & 6 & $11.9-33.6$ & 5.52 & 300 & 81 \\
$25 \mathrm{Apr}$ & 33 & $16.3-17.5$ & 5.52 & $150,200,300,350,400$ & 395 \\
$26 \mathrm{Apr}$ & 61 & $14.4-22.3$ & $2.22-5.92$ & 250,300 & 140 \\
$27 \mathrm{Apr}$ & 45 & $16.5-28.7$ & 5.53 & 300 & $96-672$ \\
$1 \mathrm{May}$ & 74 & $16.7-22.4$ & 5.53 & $250,300,350,400$ & 220 \\
2 May & 40 & $17.8-28$ & 5.57 & $250,300,325,450$ & $127-2230$ \\
2 May & 29 & $17.8-28$ & $3.35-5.57$ & 300 & $81-86$ \\
\hline
\end{tabular}

* when particles were exposed to gaseous exhaust.

to $33.5 \%$, resulting from the mixing of high $\mathrm{RH}$ in the engine exhaust with the dry dilution air.

The HR-ToF-AMS measures particle chemical composition between 50-700 $\mathrm{nm}$ vacuum aerodynamic diameter (Liu et al., 2007); in the present experiments, the monodispersed seed particles were selected from 150 to $450 \mathrm{~nm}$ mobility diameter $\left(d_{\mathrm{m}}\right)$, equivalent to 206 to $619 \mathrm{~nm}$ vacuum aerodynamic diameter $\left(d_{\mathrm{va}}\right)$ for $\mathrm{NH}_{4} \mathrm{NO}_{3}$ particles. Secondary dilution ratios at the introduction point of the seed particles/primary exhaust gases into the flow tubes varied between 11 to 200, resulting in a total dilution ratio range of 81 to 2230. No active control of RH and temperature was used, and thus the RH was mostly influenced by the water vapor in the primary gas exhaust mixing with zero air, resulting in a relatively low RH of $33 \%$ in the flow tubes. Even in this low range, the seed sulfate particles are expected to be deliquescent (Onasch et al., 1999) and the nitrate particles are expected to contain water with the organic contents (Prenni et al., 2003).

\section{Results and discussions}

\subsection{Characterization of primary dilute gaseous emissions}

The average $\mathrm{THC}$ and $\mathrm{NO}_{\mathrm{x}}$ concentrations in the primary dilute exhaust in the CVS for the multiple repeats of each engine mode are listed in Table 1. CO was below the instrument detection limit in the primary dilute exhaust except during idling, indicating that the catalyst reached its minimum operating temperature for all three modes. The $\mathrm{NO}_{\mathrm{x}}$ concentration for Mode 1 was about 3 times higher than for Modes 2 and 3, reflecting the higher torque of this mode that requires significantly higher fuel burns and higher combustion temperature than the other two modes. As a result, THC concentrations, expressed in ppmC, was also typically higher for Mode 1 than the other modes, even though it varied within a narrow range of 5.5-6.8 ppmC among the three modes. This reflects the relatively stable working conditions of the catalyst. On the other hand, the ratio $\mathrm{THC} / \mathrm{CO}_{2}$, a surrogate for the emission factor for THC, was the lowest for Mode 1 at $(6.5 \pm 0.2) \times 10^{-4}$ compared with those for Mode 2 and 3 at $(1.0 \pm 0.1) \times 10^{-3}$, and $(7.1 \pm 0.4) \times 10^{-4}$, respectively, indicating a more efficient fuel combustion at higher temperature. The SVOCs in the THC mixture, not separately quantified, are expected to be in equilibrium with organics in the primary particles in the exhaust. The SVOCs are also available for further condensation onto existing ambient particles once the exhaust gas is mixed with the ambient air. This process and the resulting particle mass are not measured in the current standard motor vehicle emission testing methods.

\subsection{Condensational uptake of SVOCs onto existing particles}

Condensation of SVOCs in engine exhaust onto existing ambient particles is expected to occur once the SVOCs come into contact with these particles. This re-partitioning of organic mass from gas to particle represents the reverse of the process of primary particle evaporation upon dilution (Robinson et al., 2007) and may result in a non-negligible source of low bias in the current vehicular particle mass emission data.

To determine the magnitude of condensation, laboratory generated seed particles of inorganic composition were used as surrogates for inorganic particles in ambient air. The seed particles were exposed to the gaseous exhaust under different experimental conditions as shown in Table 2.

Condensational uptake of SVOCs onto the particles was observed in all experiments. To generalize the main findings, this organic uptake has approximately a linear dependency on the available seed particle mass as represented by sulfate under each set of experimental conditions. Experiments using different seed chemical compositions (nitrate vs. sulfate) revealed similar linear relationships. Different 


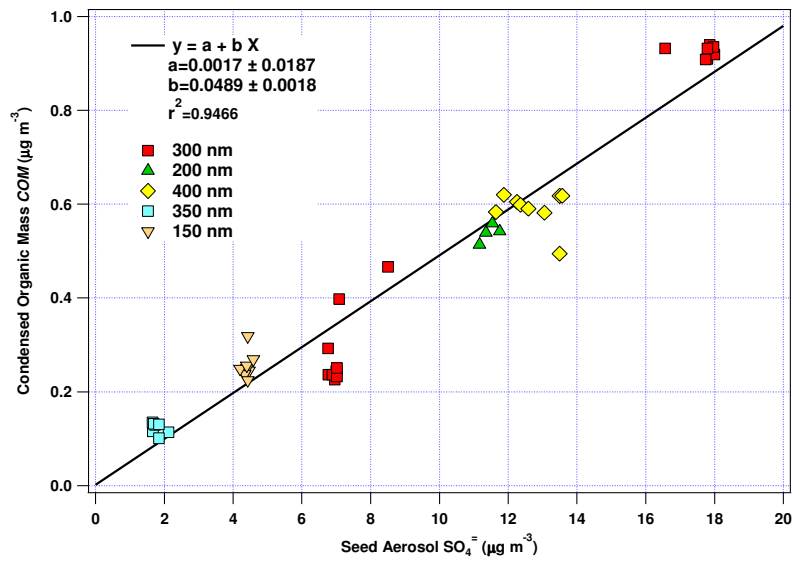

Fig. 2. The condensed organic mass (COM) on neutral sulfate seed particles. It is approximately a linear function of the available sulfate particle mass regardless of particle size.

exposure times of the particles to the THC, between 1.5 to 7 min, produced no discernable differences in the condensational uptake. On the other hand, the exposures to different levels of THC resulted in linear dependencies with significantly different slopes. These THC levels varied over orders of magnitude due to a combination of different engine running modes (Table 1) and different dilution ratios.

To illustrate these general findings, Fig. 2 shows the results obtained for Mode 2 experiments on April 25, revealing the condensed organic mass (COM) as an approximately linear function of seed particle sulfate mass. In these experiments, the seed particles were neutral, and the total dilution ratio of the gaseous exhaust was kept constant at 395 resulting in a constant THC (Tables 1 and 2). Furthermore, the contact time between the seed particles and the diluted gaseous exhaust remained constant at $5.5 \mathrm{~min}$. The variables in the experiments shown in Fig. 2 are the particle sizes and number concentrations of the seed particles that resulted in different seed particle mass loadings. The linear dependency of the COM on the seed particle sulfate is highly significant $\left(r^{2}=0.95\right)$

\subsection{Dilution effects on the condensation processes}

As demonstrated above, organic materials are taken up onto the seed particles as a result of re-partitioning from the gas phase. A steady-state of COM with gas phase concentrations is expected to be established in milliseconds to seconds for typical accumulation mode ambient aerosol particles (Seinfeld and Pandis, 1998), and COM is expected to be influenced by the vapor pressures of the SVOCs, and hence by the degree of dilution. Fig. 2 shows that under a dilution ratio of 395 , COM depends approximately linearly on the seed particle mass regardless of the particle sizes (from 150 to
$450 \mathrm{~nm})$, i.e.,

$\mathrm{COM}=a+S \cdot M_{\mathrm{s}}$

where $M_{\mathrm{S}}$ is the mass concentration of the seed particles in a unit air volume and dominated by $\mathrm{SO}_{4}^{=}$, and $\mathrm{COM}$ is the amount of condensed organic mass concentration in the same air volume, again determined by the HR-ToF-AMS. Results show that under most experimental conditions, the intercept $a$ is not significantly different from 0 . Therefore, the slope of the curve $S$ can be given by,

$S=\frac{\Delta \mathrm{COM}}{\Delta M_{\mathrm{s}}}=\mathrm{COM} / M_{\mathrm{S}}$

The quantity $S$ is the condensed organics to seed particle mass ratio. Using a simple model of one chemical compound to represent the organics in both the gas and condensed phase, under gas-particle equilibrium, the concentration $(C)$ of the carbon in the condensed organics in the seed particles (in unit of $\mathrm{g}^{-1}$ ) is determined by the vapor pressure $\mathrm{P}_{\mathrm{THC}}$ as governed by Henry's law

$P_{\mathrm{THC}}=K_{\mathrm{H}} C$

where $K_{\mathrm{H}}$ is the effective Henry's law constant in ppmC $\left(\mathrm{g}^{-1}\right)^{-1}$, and $P_{\mathrm{THC}}$ is the partial pressure of the THC in ppmC. Since COM is small compared to $M_{\mathrm{S}}$ (Fig. 2), $C$ is approximately proportional to $S$

$$
C=\frac{f \cdot \mathrm{COM}}{\left(\mathrm{COM}+M_{\mathrm{s}}\right) / d}=f d \cdot \frac{\mathrm{COM} / M_{\mathrm{s}}}{\left(\mathrm{COM} / M_{\mathrm{s}}+1\right)}=\frac{f d \cdot S}{S+1} \approx f d \cdot S
$$

or

$S \approx \frac{C}{f d}=\frac{P_{\mathrm{THC}}}{f d \cdot K_{\mathrm{H}}}$

where $d$ is the density of the particles in $\mathrm{g}^{-1}$, and $f$ is the mass fraction of carbon in COM. Eq. (5) indicates that $S$ is proportional to the equilibrium organic carbon mass concentration in the seed particles as determined by Henry's Law and therefore by the gas phase partial pressure of THC. Thus, $S$ represents the amount of dissolution of organics in the seed particles as determined by equilibrium partitioning between SVOCs and the particles. As further explored below, the relationship between $S$ and $P_{\text {THC }}$ was in fact not linear, suggesting that the $K_{\mathrm{H}}$ may not be a constant with changing $P_{\mathrm{THC}}$.

In general, for a situation where significant re-partitioning from the gas phase to particles occurs due to increases in seed particle mass $M_{\mathrm{s}}$, both $P_{\mathrm{THC}}$ and $C$ will decrease, as can be derived from the Henry's law:

$P_{\mathrm{THC}}=K_{\mathrm{H}} \mathrm{C}=P_{\mathrm{THC}}^{0}-\frac{10^{3} \cdot f \cdot \mathrm{COM}}{W} \cdot \frac{R T}{P}$

where $P_{\mathrm{THC}}^{0}$ is the original partial pressure of THC before condensation in ppmC, $W$ is the atomic weight of carbon, 
$R$ is the gas constant, $T$ is temperature, and $P$ is the ambient pressure and equals to $1 \mathrm{~atm}$ for the current experiments. Combining Eqs. (6) with (4) yields

$$
P_{\mathrm{THC}}^{0}-\frac{10^{3} \cdot f \cdot \mathrm{COM}}{W} \cdot \frac{R T}{P}=K_{\mathrm{H}} \frac{f \cdot \mathrm{COM}}{\left(\mathrm{COM}+M_{\mathrm{s}}\right) / d}
$$

This is further reduced to a quadratic equation for $\mathrm{COM}$

$a \mathrm{COM}^{2}+\left(f d K_{\mathrm{H}}-P_{\mathrm{THC}}^{0}+a M_{\mathrm{s}}\right) \mathrm{COM}-P_{\mathrm{THC}}^{0} M_{\mathrm{s}}=0$

where $a=\frac{10^{3} \cdot f}{W} \cdot \frac{R T}{P}$ is a constant. Hence, COM should be approximately a quadratic equation of $M_{\mathrm{s}}$.

The level of the decrease in $\mathrm{P}_{\mathrm{THC}}$ from $P_{\mathrm{THC}}^{0}$ (Eq. 6) is dependent on the level of COM and therefore $M_{\mathrm{s}}$. Within the range of $M_{\mathrm{S}}$ used in the present experiments, the magnitude of COM compared to $\mathrm{P}_{\mathrm{THC}}$ is insignificant, and hence Eq. (8) can be simplified to a linear relationship between COM and $M_{\mathrm{s}}$. For example, for the experiments shown in Fig. 2, with a total dilution ratio of $395, P_{\mathrm{THC}}$ is calculated to be $0.377 \mathrm{ppmC}$ using the results in Table 1. COM is less than $1 \mu \mathrm{g} \mathrm{m}^{-3}$ for the seed sulfate particle mass range (Fig. 2), or $<2 \times 10^{-3} \mathrm{ppmC}$ assuming an $\mathrm{H}: \mathrm{C}$ elemental ratio of 1.2 in the organics, at least 200 times lower than $P_{\mathrm{THC}}$. Thus $P_{\text {THC }}$ was effectively a constant with regard to the condensational uptake during the experiments, which led to an approximately constant $C$ and therefore $S$. As shown by the results in Fig. 2, COM was indeed approximately linearly related to $M_{\mathrm{s}}$, supporting the arguments above.

The situation can change if $M_{\mathrm{S}}$ increases dramatically. For example, for the experiments shown in Fig. 2, if $M_{\mathrm{s}}$ were increased by 100 times from the range used in the experiments (to about $2 \mathrm{mg} \mathrm{m}^{-3} \mathrm{SO}_{4}^{=}$, an unrealistic atmospheric concentration), COM would be equivalent to $<0.2 \mathrm{ppmC}$, or about half of $P_{\mathrm{THC}}$. Under this situation, $\mathrm{P}_{\mathrm{THC}}$ may indeed start to experience noticeable decreases after condensation occurs, and $S=\mathrm{COM} / M_{\mathrm{S}}$ will no longer be a constant with respect to changes in $M_{\mathrm{s}}$.

The condensational uptake occurred either through adsorption onto the surface of the seed particles or dissolution into the seed particles, or a combination of the two. To determine which process was responsible, $S$ is derived following Eq. (2) for each of the five sizes of the seed particles for the experiments shown in Fig. 2, and plotted in Fig. 3 as a function of the surface area of a single seed particle for the five sizes. Also plotted in Fig. 3 are the ratios COM/ $M_{\mathrm{S}}$ for either the pure dissolution (blue dash line) and adsorption processes (red dash line) versus the surface area of a seed particle. For a dissolution process that reaches equilibrium with gas phase, the ratio $\mathrm{COM} / M_{\mathrm{S}}$ remains a constant regardless of particle sizes. Adsorption of organics onto the seed particles, on the other hand, depends on the available surface area, leading to an inverse relationship between the ratio $\mathrm{COM} / M_{\mathrm{S}}$ and particle surface area. Fig. 3 clearly shows that COM is due to dissolution rather than surface adsorption, having exhibited no dependence on the particle surface area.

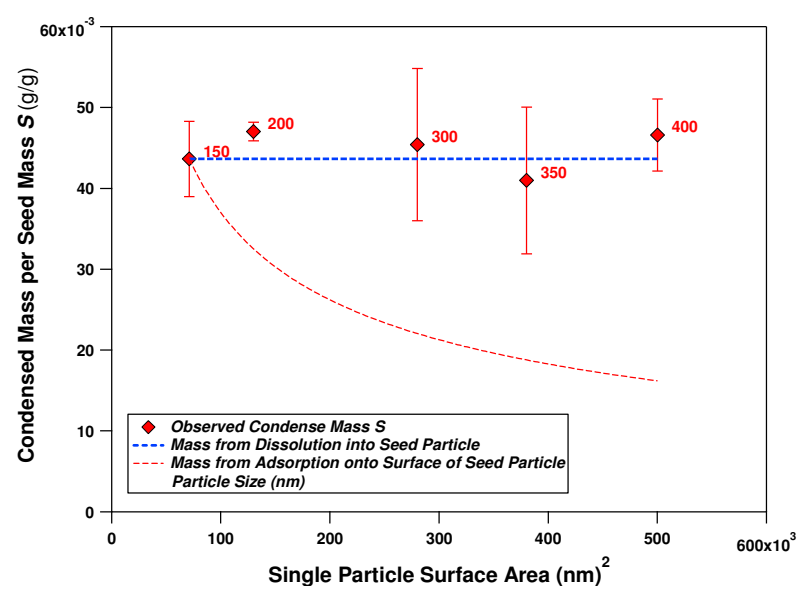

Fig. 3. The $\mathrm{COM} / M_{\mathrm{S}}$ as observed, $S$, are derived as the slopes of organic mass versus seed particle mass for different particle sizes (e.g., Fig. 2). Condensed mass from dissolution in the particle, relative to that at $150 \mathrm{~nm}$ seed particle, does not change with particle sizes (heavy dashed line); that from pure adsorption onto particle surface varies inversely with the surface area (light dashed line). The uncertainties in the slopes of COM versus seed particle mass are plotted for each $S$ value.

Figure 4 shows the results of experiments specifically designed to test the response of $S$ to different final dilution ratios over a range from 81 to 2230 . Plotted in the figure is $S$ versus the dilution ratios for near constant RH and temperature, but for different seed particle composition, sizes, and engine modes. Figure $4 \mathrm{a}$ shows $S$ for separate $\left(\mathrm{NH}_{4}\right)_{2} \mathrm{SO}_{4}$ and $\mathrm{NH}_{4} \mathrm{NO}_{3}$ seed particles, showing that $S$ for both types of seeds is essentially the same and exhibits the same response to dilution. Fig. 4b shows $S$ for $\left(\mathrm{NH}_{4}\right)_{2} \mathrm{SO}_{4}$ seed particles under different engine modes, again showing similar responses to dilution.

There is a marked decrease in $S$ as the dilution ratio $(D)$ increases. Such a dependency is similar to those reported for the primary particle mass emissions in low-load diesel engine exhaust and in wood smoke exhaust (Lipsky et al., 2006). Robinson et al. (2007) observed a declining primary organic mass emission factor for diesel engines as a function of dilution ratio. For the gasoline exhaust studied here, a power function

$S=(0.024 \pm 0.09)+7305 D^{-(2.39 \pm 0.03)}$

was fitted to the data, $D$ being the dilution ratio, with a correlation coefficient $r^{2}=0.90$ for the fit. The value of $S$ dropped from $0.23 \mathrm{~g} \mathrm{~g}^{-1}$ at $D=81$, to $0.025 \mathrm{~g} \mathrm{~g}^{-1}$ at $D=2230$, dropping by a factor of 9.2. In comparison, for diesel exhaust particles, a reduction by a factor of approximately 2 is reported over the same dilution range but this was attributed to the volatility of SVOCs on the diesel particles (Robinson et al. 2007). 


\subsection{Magnitude of COM versus primary organic aerosols (POA)}

The significance of COM can be cast in light of its relative importance to the primary particles. The primary particles from the gasoline engine were likely dominated by organic mass (Mohr et al., 2011; Schauer et al., 2002) that is partitioned between gas and particles. The partitioning between the gas phase and the primary particles should be determined by the vapor pressures of compounds in the THC mixture. Unfortunately, no primary particle mass and THC data were collected in the flow tubes for the direct comparison.

However, the partitioning between the gas phase and the primary particles in the exhaust in the CVS can be calculated. First, the primary organic aerosol (POA) mass concentration in air (in unit of $\mu \mathrm{g} \mathrm{m}^{-3}$ ), $C_{\mathrm{pp}}$, is estimated from the primary aerosol mass calculated using the particle number size spectra from the SMPS measurements and assuming a density of $1.4 \mathrm{~g} \mathrm{~cm}^{-3}$ (Larson et al., 1998; Park et al., 2003) and a ratio of organic carbon mass/total mass of $43.7 \%$ (Schauer et al., 2002). The calculated primary particle mass concentrations were compared and verified with several Teflon-filter based mass measurements. The total hydrocarbon concentration in the CVS $\left(C_{\mathrm{THC}}, \mu \mathrm{g} \mathrm{m}^{-3}\right)$ is calculated using the THC data (which are reported as $P_{\mathrm{THC}}$ in units of ppmC) assuming an $\mathrm{H} / \mathrm{C}$ atomic ratio of 1.2 . The fraction, $F_{\mathrm{pp}}$, of the THC present in the primary particles in the CVS is calculated to be $0.11 \pm 0.06$ using

$$
F_{\mathrm{pp}}=\frac{C_{\mathrm{pp}}}{C_{\mathrm{pp}}+C_{\mathrm{THC}}}=\frac{C_{\mathrm{pp}}}{C_{\mathrm{pp}}+2 \times 10^{-3} P_{\mathrm{THC}}}
$$

where $C_{\mathrm{THC}}=2 \times 10^{-3} P_{\mathrm{THC}}$ is a conversion from partial pressure to air concentration at $25^{\circ} \mathrm{C}$ and $1 \mathrm{~atm}$. $F_{\mathrm{pp}}$ did not change significantly over the narrow range of dilution ratios of 14-22 inside the CVS; however, it should decrease with further dilution in the flow tube since $C_{\mathrm{pp}}$ is expected to decrease faster than $C_{\mathrm{THC}}$ due to evaporative loss of volatile organic components from the primary particles.

An aggregate partitioning coefficient $K_{\mathrm{p}}$ may be defined for the condensational uptake shown in Fig. 2 using

$K_{\mathrm{p}}=\frac{\mathrm{COM} / M_{\mathrm{s}}}{C_{\mathrm{THC}}}=\frac{S}{2 \times 10^{-3} P_{\mathrm{THC}}}$

or, $S=2 \times 10^{-3} K_{\mathrm{p}} P_{\mathrm{THC}} ; P_{\mathrm{THC}}$ is the partial pressure of THC in the flow tube and changes with the different dilution ratios. It should be noted that a true partitioning coefficient of a compound is determined only by its particle and gas phase concentrations, but in the absence of speciation information in both phases, the aggregate partitioning coefficient $K_{\mathrm{p}}$ as defined in Eq. (11) provides a convenient tool for modeling the organic mass that may reside in ambient particles from condensation of THC compounds in the engine exhaust. Comparing Eqs. (11) and (5), it is clear that $K_{\mathrm{p}}$ is inversely related to the Henry's law constant $K_{\mathrm{H}}$ for the dissolving THC in the inorganic particles.
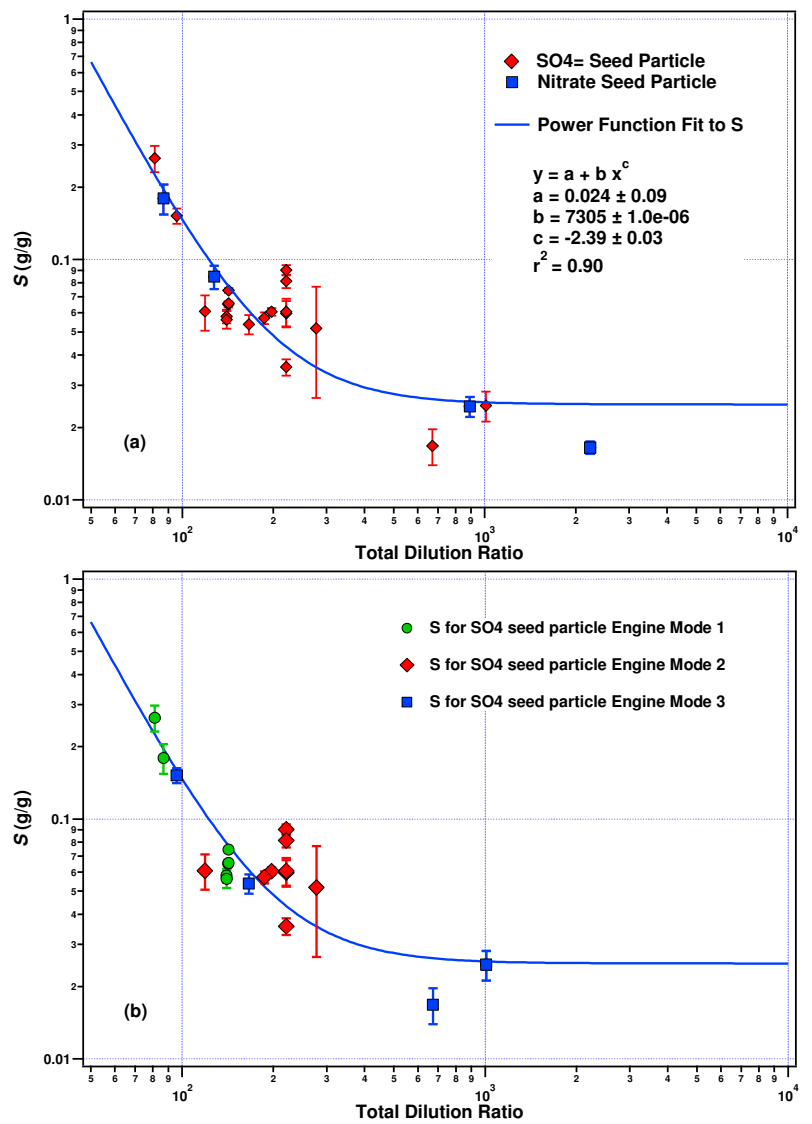

Fig. 4. The amount of dissolution $S$ of the organic matter in the inorganic seed particles (condensed organic mass per unit mass of seed particles) in $\mathrm{g} \mathrm{g}^{-1}$ unit versus total dilution ratios from 81 to 2230. The uncertainties in $S$ are derived from the linear fits to COM versus seed particle mass. (a) Red diamonds are for for $\left(\mathrm{NH}_{4}\right)_{2} \mathrm{SO}_{4}$ seed particles of all engine modes; blue squares are for $\mathrm{NH}_{4} \mathrm{NO}_{3}$ seed particles in engine mode 1 . (b) $S$ for $\left(\mathrm{NH}_{4}\right)_{2} \mathrm{SO}_{4}$ seed particles in engine modes 1,2 , and 3 .

Figure 5 shows a plot of $S$ versus $C_{\mathrm{THC}}$, showing nonlinear increases in $S$ with increasing $C_{\mathrm{THC}}$. Similar to Fig. 4, the $S$ responses to $C_{\mathrm{THC}}$ are separated by the seed particle composition $\left(\mathrm{NH}_{4} \mathrm{NO}_{3}\right.$ versus $\left(\mathrm{NH}_{4}\right)_{2} \mathrm{SO}_{4}$ seeds, Fig. 5a) and by the different engine mode for $\left(\mathrm{NH}_{4}\right)_{2} \mathrm{SO}_{4}$ seed particles (Fig. 5b). A power function fitted to $S$ versus $C_{\mathrm{THC}}$ yields

$S=(0.012 \pm 0.0001)+(1.37 \pm 0.28) \times 10^{-4} C_{\mathrm{THC}}^{(2.53 \pm 0.76)}$

with a correlation coefficient $r^{2}=0.81$ for the fit. The value of $S$ increases from $0.012 \mathrm{~g} \mathrm{~g}^{-1}$ to $0.26 \mathrm{~g} \mathrm{~g}^{-1}$ with $C_{\mathrm{THC}}$ increasing from 1 to $18 \mathrm{\mu g} \mathrm{m}^{-3}$ (over the range of the dilution ratios between 81.5 to 2230). As shown in Fig. 5, the responses are consistent between the two types of seed particles, and among the different engine modes. The nonlinearity shows that the partitioning coefficient $K_{\mathrm{p}}$, being the derivative of the function given in Eq. (12), is not a constant 

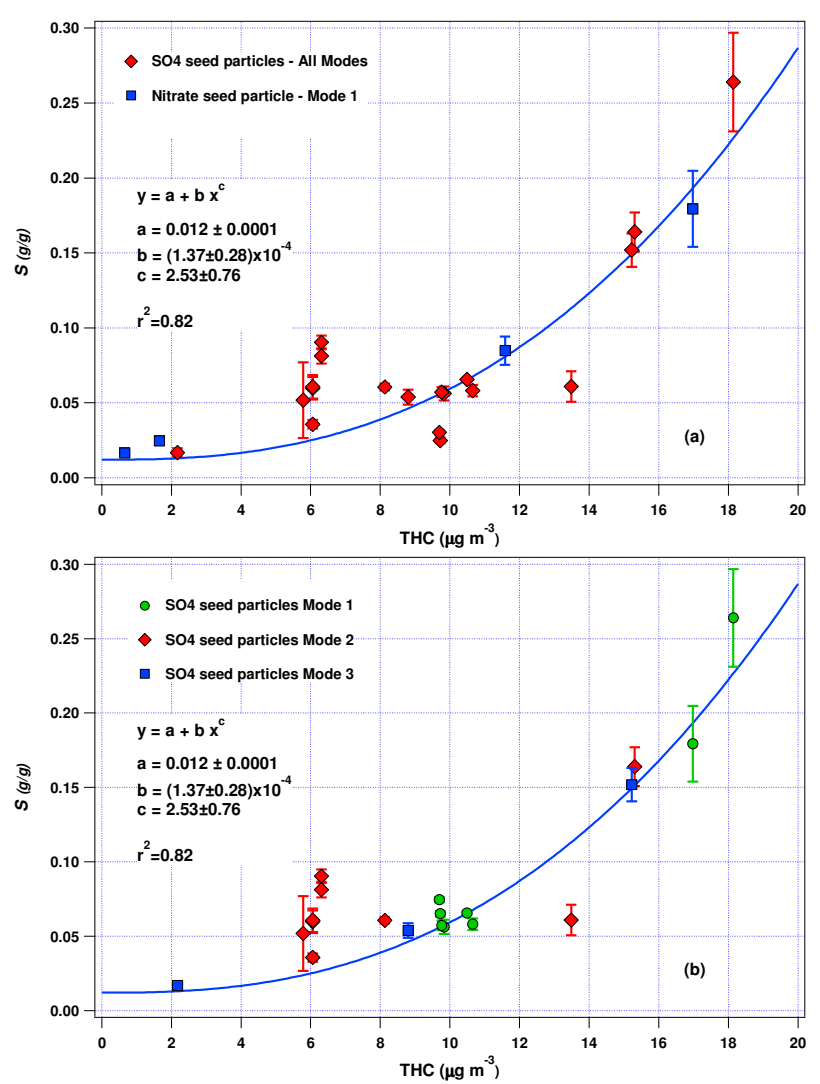

Fig. 5. The amount of dissolution of organic mass in inorganic particles, $S$, in $\mathrm{g} \mathrm{g}^{-1}$ unit versus the concentrations of THC in the gasoline engine exhaust, $C_{\mathrm{THC}}$. A non-linear increase in $S$ is observed with increasing $C_{\mathrm{THC}}$. The relationship is fitted with a power function as shown by the fitted curve. The uncertainties in $S$ are derived from the linear fits to COM versus seed particle mass. (a) Red diamonds are $\mathrm{S}$ for $\left(\mathrm{NH}_{4}\right)_{2} \mathrm{SO}_{4}$ seed particles of all engine modes; blue squares are for $\mathrm{NH}_{4} \mathrm{NO}_{3}$ seed particles in engine mode 1. (b) $S$ for $\left(\mathrm{NH}_{4}\right)_{2} \mathrm{SO}_{4}$ seed particles in engine modes 1,2 , and 3 .

with respect to $C_{\mathrm{THC}}$. It increases from $0.0004\left(\mu \mathrm{g} \mathrm{m}^{-3}\right)^{-1}$ at $C_{\mathrm{THC}}=1 \mu \mathrm{g} \mathrm{m}^{-3}$, to $0.03\left(\mu \mathrm{g} \mathrm{m}^{-3}\right)^{-1}$ at $C_{\mathrm{THC}}=18 \mu \mathrm{g} \mathrm{m}^{-3}$, increasing by $>100$ times. The intercept $(0.012 \pm 0.0001)$ in the power function of Eq. (12) implies that at very high dilutions, the value of $S$ becomes asymptotic. The relative size of this intercept may represent irreversible condensation versus reversible equilibrium, similar to olefin reactions with sulfate seed particles (Liggio and Li, 2008). Regardless, this intercept is small compared to $S$, and could be a result of the choice of fitting function. Clearly, more experiments will be needed to determine the significance of the intercept with regard to the possibility of irreversible condensation.

The relationship between $S$ and $C_{\mathrm{THC}}$ suggests that, as $C_{\mathrm{THC}}$ increases, proportionally more organics are partitioned into the particles. Since the uptake was determined mostly by dissolution of organics (see Fig. 3), the increasing $S$ with $C_{\mathrm{THC}}$ may be due to enhanced solubility with the higher or- ganic content of the inorganic seed particles at the higher $C_{\text {THC }}$. Other factors not included in a simple solubility partitioning model, which can enhance the organic uptake and increase the amount of dissolution under higher $C_{\mathrm{THC}}$, include potential organic reactions in the particles (Liggio et al., 2007; Hallquist et al., 2009).

To compare the partitioning of THC to the seed particles and the partitioning of THC on the primary particle, the partitioning of THC to the seed particles is calculated as:

$F_{\mathrm{com}}=\frac{\mathrm{COM}}{C_{\mathrm{THC}}^{0}}=\frac{S \cdot M_{\mathrm{s}}}{C_{\mathrm{THC}}^{0}}$

where $C_{\mathrm{THC}}^{0}$ is the initial THC concentration before dilution in unit of $\mu \mathrm{g} \mathrm{m}^{-3}$. Equation (13) shows that $F_{\text {com varies lin- }}$ early with respect to $S$ if $M_{\mathrm{s}}$ and $C_{\mathrm{THC}}^{0}$ are fixed. For the experiments $C_{\mathrm{THC}}^{0}$ changed significantly while $S$ varied over the dilution range of 81 to 2230 (Fig. 4). However, there are no corresponding changes in the aggregate partitioning coefficient $K_{\mathrm{p}}$ with the dilution ratio, suggesting that diluting both the gas and particle phase SVOCs did not cause systematic shifts in partitioning between the two phases.

For an $M_{\mathrm{S}}$ of $15 \mu \mathrm{g} \mathrm{m}^{-3}$ Eq. (13) yields an $F_{\text {com }}$ between 0.02 and 0.21 and averages $0.12 \pm 0.06$. For an $M_{\mathrm{S}}$ of $30 \mu \mathrm{g} \mathrm{m}^{-3}, F_{\text {com }}$ rises to a range between 0.07 to 0.4 and averages $0.21 \pm 0.09$. Considering that $F_{\mathrm{pp}}$ is estimated at 0.11 for the low dilution situation inside the CVS and should decrease with further dilutions, $F_{\text {com }}$ will be equivalent to $F_{\mathrm{pp}}$ at $M_{\mathrm{s}}$ lower than $15 \mu \mathrm{g} \mathrm{m}^{-3}$. Thus, in moderately polluted atmosphere, the condensational uptake of SVOCs on inorganic particles can account for significant fractions of the THC emitted from gasoline engines, fractions that are equivalent to the fraction of THC partitioning on primary particles.

\subsection{Organic composition of COM versus primary organic aerosol (POA)}

In the current experiments, primary organic aerosol (POA) particles from the gasoline engine were filtered before the exhaust gas was exposed to the seed particles (Fig. 1) rather than allowing the POA to interact with the seed particles. In theory, transfer of semivolatile organics from the POA to the seed particles can occur, first through evaporation of semivolatiles followed by condensation of the evaporated components to the seed particles, resulting in COM. This process might have contributed more mass to COM, accompanied by a loss of organic mass from the POA. However, as demonstrated below with estimates of evaporative mass from POA and with differences in chemical composition between POA and COM, this potential mass transfer from POA to $\mathrm{COM}$ is negligible.

Firstly, this mass transfer can be estimated as follows. The primary organic mass was $11 \%$ of the THC based on Eq. (10) at relatively low dilution ratios of 14-22 in the CVS (and should be lower at higher dilution ratios). Assuming that the 
maximum evaporative loss fraction for the POA from further dilution over the current dilution range was about $67 \%$, similar to that reported by Robinson et al. (2007), the evaporated mass from the POA would be approximately $7 \%$ of the total gas phase THC. Of this evaporated organic mass, most would remain in the gas phase after repartitioning to the seed particles. The value of $F_{\text {com }}$ obtained using Eq. (13) can be used as an estimate for the fraction of the evaporated POA which re-partitions onto the seed particles. At $M_{\mathrm{s}}=15 \mu \mathrm{g} \mathrm{m}^{-3}$, the value of $F_{\text {com }}$ is 0.12 and the condensed fraction is $10 \%$ of the total evaporated POA. In fact, as discussed below, the particle-bound fraction of the evaporated POA would be even smaller than this $F_{\text {com }}$ value would indicate since $\mathrm{COM}$ was comprised of different species than POA. Thus, the repartitioning of the evaporated POA would contribute $<7 \%$ of the COM on the seed particles, and $<10 \%$ of the evaporated POA would condense as COM.

Secondly, the chemical composition of POA and COM was different, suggesting that the potential contribution to COM from the repartitioning of the evaporated POA was even smaller than the above analysis based on partitioning of the bulk THC. The organic mass spectrum of POA was not determined by the AMS in the current study. However, an organic mass spectrum was published for POA from a gasoline engine by Mohr et al. (2009), showing the largest fragments at $m / z 43$ and 57, with fragments ratios of $m / z 43 / 44$ and 57/44 of 6.80 and 6.32, respectively. Furthermore, the ratio $m / z 44$ to total organics in the reported POA is 0.017 . These values are further supported by ambient measurements results which suggest that primary combustion aerosols in general are dominated by hydrocarbon-like organic aerosols (HOA) (Ng et al., 2011 and references therein). HOA, derived from statistical analysis of ambient AMS organic mass spectra from many field studies, has the maximum organic fragment at $m / z, 43$ and a prominent fragment at $m / z 57$, with a ratio of $m / z 43$ to $m / z 44$ of 6.9 and a $m / z 57 / 44$ ratio of 5.52 (Ng et al., 2011), consistent with the reported POA from gasoline engines (Mohr et al., 2009).

In comparison, the typical organic mass spectrum of COM, in Fig. 6, shows the largest organic fragment at $m / z$ 44, and the fragments $m / z 43$ and 57 are small. The $m / z 43 / 44$ mass ratio (0.59) in COM is a factor of 12 lower, and the $\mathrm{m} / \mathrm{z} 57 / 44$ ratio (2.91) a factor of 2.2 lower, than that for the POA reported by Mohr et al. (2009). The ratio of fragment $\mathrm{m} / \mathrm{z} 44$ to total organics is $0.097,5.7$ times higher than that of POA reported by Mohr et al. (2009). Therefore, COM is significantly different than either the POA or the HOA, containing a higher oxygen content than either aerosol types. The organic mass spectrum of COM demonstrates that the oxygenated SVOCs in the gasoline engine emissions were likely the more active condensing organics compared to the hydrocarbons. This makes it much less likely for POA repartitioning and re-condensation to be important to COM.

This oxygen-containing COM is consistent with lab studies that showed large and fast uptake of carbonyls

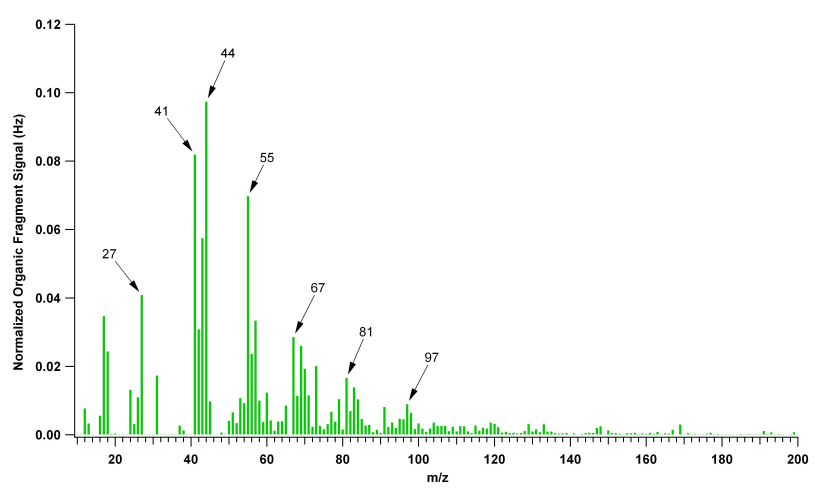

Fig. 6. The average spectrum of the normalized organic mass spectra for the condensed organic mass (COM) on sulfate seed particles. The average spectrum was obtained for all the same experiments as those shown in Fig. 2.

on seed particles (Liggio et al., 2005, 2007). In light duty gasoline vehicle emissions, carbonyls can be approximately $5-10 \%$ of the hydrocarbons (Graham, 2005), which is consistent with the profiles published by the US EPA (http://cfpub.epa.gov/si/speciate/ehpa_speciate_browse_ source.cfm?ptype $=\mathrm{G}$ ) and by Shauer et al. (2002). Although small, this oxygenate proportion in the VOCs from gasoline engine emissions may be sufficient to lead to the high oxygen content seen in the COM. This oxygen-containing primary organic mass on seed particles would in fact help solve the issue (at least partially) that models typically under-predicted SOA.

\subsection{Significance of condensational uptake: AURAMS regional air quality modeling}

To test the significance of COM on a regional scale, a unified regional air quality modelling system, AURAMS (Gong et al., 2003; Stroud et al., 2008; Cho et al., 2009; Smyth et al., 2009; Slowik et al., 2010; also see Supporting Information, SI), was used to model the gasoline exhaust emissions and subsequent condensation of SVOCs onto $\mathrm{SO}_{4}^{=}$ aerosol. Gasoline exhaust total organic vapor (THC) was treated as an additional gas-phase species in the mobile stream of the emissions processing system. THC was emitted, transported, lost by gas-phase chemistry, and allowed to reach equilibrium partitioning with $\mathrm{SO}_{4}^{=}$aerosol using Eq. (12). AURAMS was run at a $15 \mathrm{~km}$ grid spacing with a domain covering eastern North America for the month of June, 2007. AURAMS produced concentration predictions for $\mathrm{PM}_{2.5} \mathrm{SO}_{4}^{=}$, gasoline engine exhaust THC, total primary organic aerosol (POA) from all sectors, 'traditional' secondary organic aerosol (SOA), gasoline engine exhaust primary particulate mass and condensed organic mass (COM) from gasoline engine exhaust. The model was run over a high pollution episode ( 24 to 27 June) and a low pollution period (20 to 23 June). 
1. $\mathrm{PM}_{2.5} \mathrm{SO}_{4}$, Clean Case, Jun $20-23$
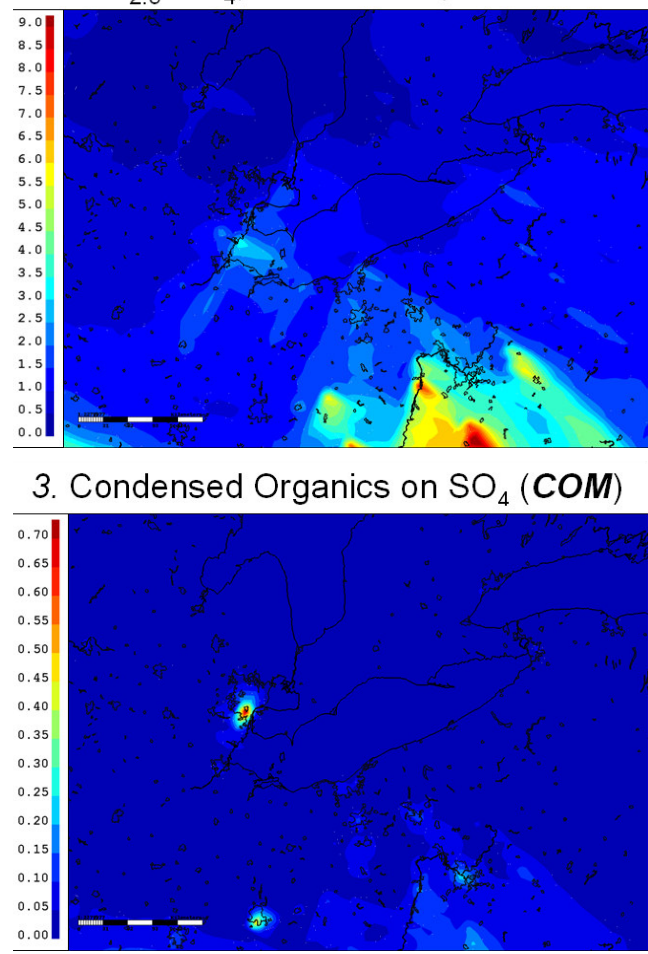

5. Gasoline Exhaust Primary $O A$

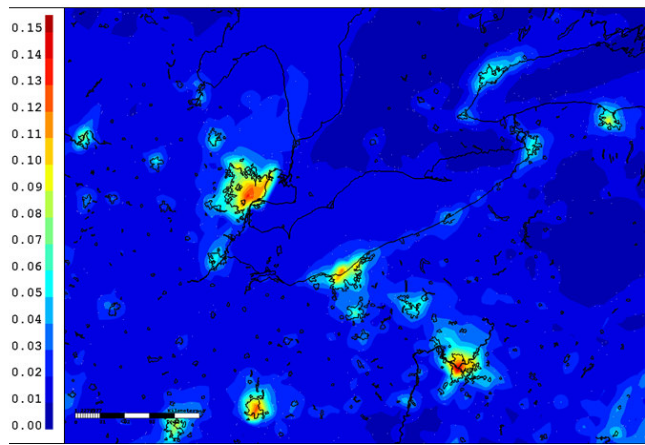

7. Ratio of COM to Total Primary OA

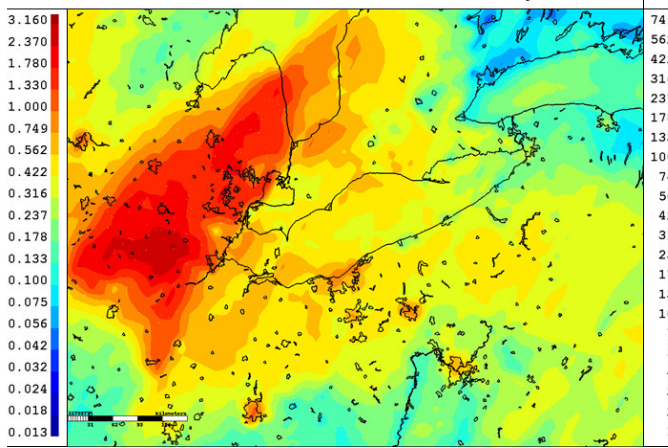

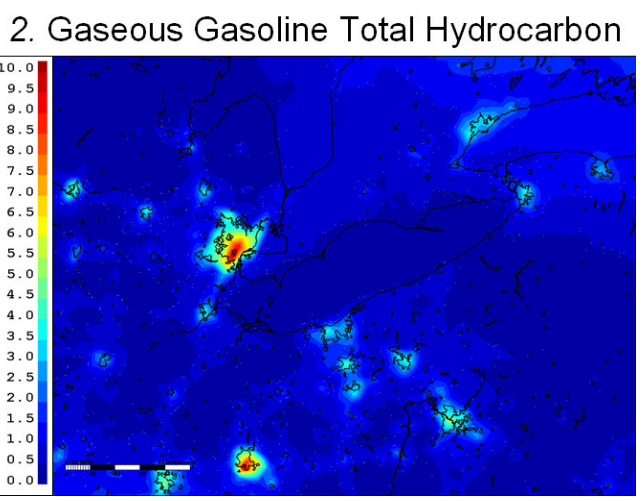
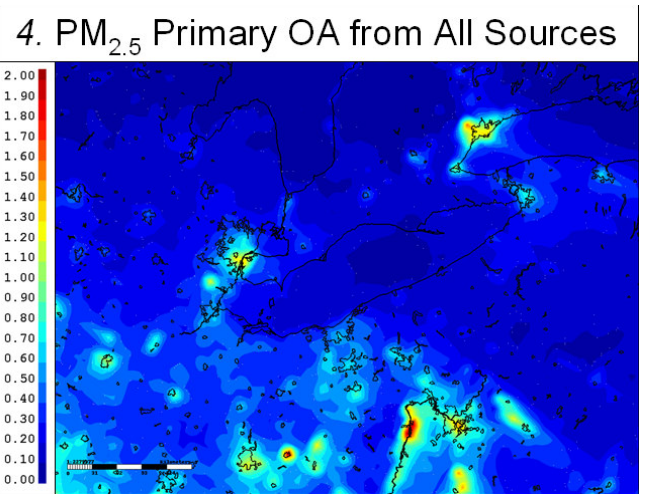

6. $\mathrm{PM}_{2.5}$ Traditional Secondary $\mathrm{OA}$

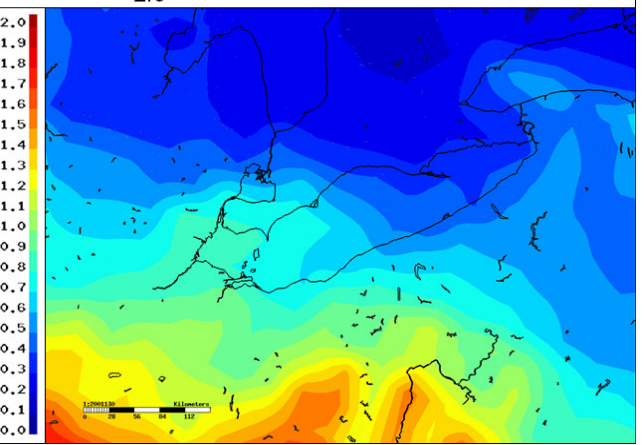

8. Ratio of COM to Gasoline Primary OA

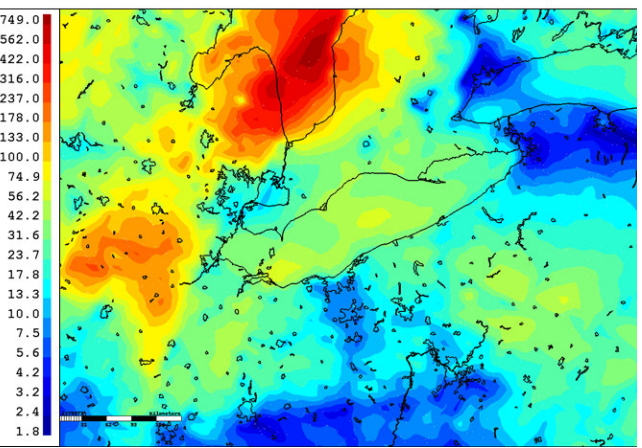

Fig. 7. AURAMS model simulation of surface level ambient aerosols in $\mu \mathrm{g} \mathrm{m}{ }^{-3}$ or ratios centering on Lake Erie. The simulation is for the polluted case from 24-27 June: (1) average surface $\mathrm{PM}_{2.5} \mathrm{SO}_{4}$; (2) gasoline engine exhaust THC; (3)COM on $\mathrm{SO}_{4}$ from the gasoline engine exhaust THC; (4) $\mathrm{PM}_{2.5}$ total primary OA mass from all sources; (5) COM from gasoline exhaust on $\mathrm{PM}_{2.5} \mathrm{SO}_{4}$; (6) $\mathrm{PM}_{2.5}$ secondary $\mathrm{OA}$ using traditional mechanisms; (7) ratio of COM to total primary OA from all sectors; (8) ratio of COM to primary OA from gasoline exhaust. The model grid resolution is $15 \mathrm{~km}$. 

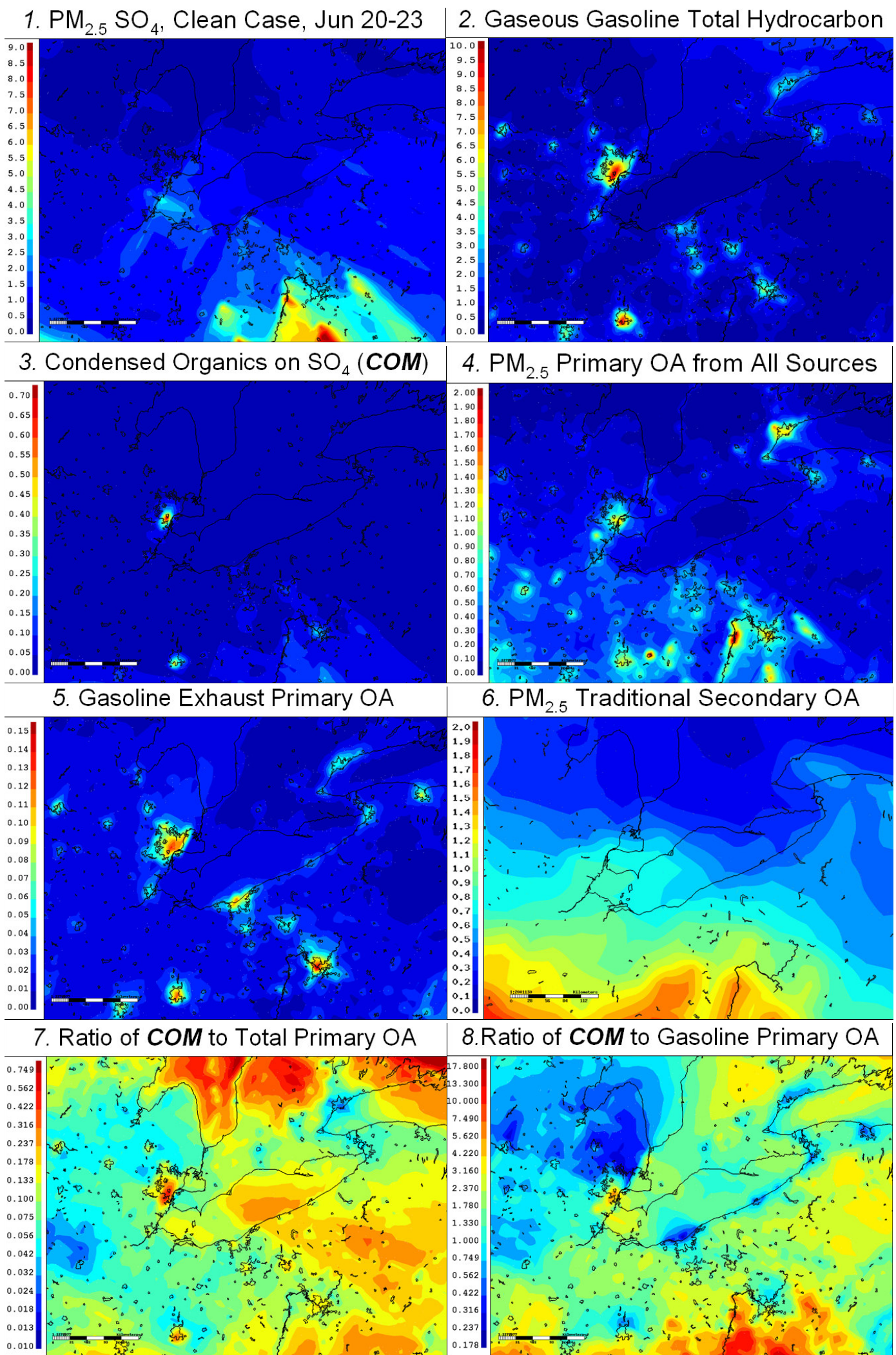

Fig. 8. Same as Fig. 7 but for the clean case of 20 June, 12:00 Universal Time to 23 June, 12:00 Universal Time. 
During the high pollution episode, southerly flow brought air rich in $\mathrm{SO}_{4}^{=}$aerosol from the Ohio Valley to the DetroitWindsor area; the maximum modeled $\mathrm{SO}_{4}^{=}$concentrations reached over $20 \mu \mathrm{g} \mathrm{m}^{-3}$ on 26 June which is consistent with measured concentrations. The model captured some of the temporal behavior of the $\mathrm{SO}_{4}^{=}$observations with a general small positive bias (Fig. S1, SI). In the Detroit-Windsor area, there were two noticeable maxima in the gasoline engine exhaust THC time series on 25 and 26 June. These days overlapped with the $\mathrm{SO}_{4}^{=}$event resulting in a large uptake of gasoline engine exhaust THC to the $\mathrm{SO}_{4}^{=}$aerosol (maximum $\mathrm{COM}$ of $20 \mathrm{\mu g} \mathrm{m}^{-3}$ ). The maximum COM from gasoline engine exhaust THC uptake was over an order of magnitude larger than the maximum gasoline engine exhaust primary organic aerosol maximum (gasoline exhaust POA, $0.7 \mu \mathrm{g} \mathrm{m}^{-3}$ ) in the urban area.

The model results also show that by condensing onto sulfate particle alone, COM from SVOCs in the gasoline engine exhaust is a significant amount in comparison with the total primary particle mass from all sources. Figure 7 shows the 3-day averaged model results over the high pollution episode from 24-27 June for a model domain centered over Lake Erie. For polluted conditions, the traditional SOA and COM were both important on regional scales and POA was only significant at urban locations. The amount of COM is higher than the total primary particle mass from all sources during the pollution episode across the model domain by a factor of up to 3 , and higher than the gasoline primary particle mass by a factor of up to 7.5. During the pollution period, COM is comparable to "traditional" SOA over a wide region of southeastern Michigan.

For cleaner conditions, Fig. 8 shows the 3-day averaged surface distributions for the period 20 to 23 June. This was a period with northwesterly winds and low $\mathrm{SO}_{4}^{=}$over Windsor. During the clean period, COM is comparable in magnitude to 'traditional' secondary organic aerosol mass within and just downwind of some major urban centers (e.g. southern Detroit). Gasoline exhaust COM in the Detroit-Windsor air shed was also comparable in magnitude to POA from all sectors. On regional scales, for the clean period, the "traditional" SOA was larger than COM or POA for most locations.

In summary, the modeling results suggest that gasoline exhaust COM could be an important component of organic aerosol within or just downwind of urban areas with coincident high sulfate aerosol loadings. It should be noted that the model application above uses $\mathrm{SO}_{4}^{=}$to derive the magnitude of COM over a regional scale. Other inorganic mass in the ambient particles may also serve as a good medium for the condensable organic materials to dissolve in, as shown in the experiments with $\mathrm{NH}_{4} \mathrm{NO}_{3}$ seed particle experiments. If these additional inorganic masses are included in the model application, $\mathrm{COM}$ will be larger than that based on $\mathrm{SO}_{4}^{=}$only, and relative to the primary particle mass the contributions from COM will be even higher over a regional scale. Furthermore, dissolution of SVOCs into the organic components in particles is probable and may further enhance COM.

\section{Implications and uncertainties}

Although COM can be significant compared to organic aerosols on a regional scale, there are a number of unresolved issues and uncertainties based on the current results. Firstly, the largest uncertainty relates to the exact identities of the condensing organic species (or classes of species) and the degree to which they contribute to the total VOC burdens. Secondly, it is unclear if fast chemical processing in the particles contributed to the measured COM and therefore altered the original chemical composition of the soluble species. Hence, the chemical speciation of the condensing organics is critically important for addressing this issue. Speciation is also important since the amount of condensation relative to the partial pressures of the condensing organics can affect the relationship between this amount and the mass of the seed particles. For example, if the partial pressure of the condensing organics is similar or small compared to COM, then increasing the seed particle mass will not result in corresponding increases in COM. Furthermore, chemical speciation information can help quantify the potential effect of POA evaporation and repartitioning into the seed particles as part of COM. A third uncertain aspect of the condensation process is whether the condensation and dissolution processes are reversible. The fourth issue is whether the dissolution process is affected by the matrix effect of the seed particle ionic strength. This may help explain partially the changing effective Henry's law constant as observed. From a purely physical condensation and dissolution perspective, one expects the processes to be reversible depending on changes in the partial pressures of the condensing organics. However, if there are chemical processes occurring on the seed particles after condensation and dissolution, part of the COM may become irreversible. Finally, the limited engine operational modes deployed may not truly reflect the real world working conditions of light duty gasoline engines. These uncertainties point to the need for further studies to provide in-depth insights into these complex processes.

Regardless of these uncertainties, the results presented here have implications for the emission databases used for modeling primary organic aerosol particles (POA), and for automotive emission control policies. The current emission data are based on results obtained under legislated methods for specific set of sampling conditions using filters at low dilution ratios (US EPA, 1993, 1996). No protocols are contained in the sampling guidelines to address the condensed organic mass on ambient particles. Thus, the primary particle mass emissions do not include the condensed organic mass as revealed in the present study. Consequently, current particle mass emissions underestimate the true POA emissions 
from automotive sources, neglecting an amount that can be similar to the primary particle mass.

\section{Supplementary material related to this article is available online at: http://www.atmos-chem-phys.net/11/10157/2011/ acp-11-10157-2011-supplement.pdf.}

Acknowledgements. Financial support for this research was provided by the PERD Particles and Related Emissions Program, Project C12.007.

Edited by: N. M. Donahue

\section{References}

Aiken, A. C., Salcedo, D., Cubison, M. J., Huffman, J. A., DeCarlo, P. F., Ulbrich, I. M., Docherty, K. S., Sueper, D., Kimmel, J. R., Worsnop, D. R., Trimborn, A., Northway, M., Stone, E. A., Schauer, J. J., Volkamer, R. M., Fortner, E., de Foy, B., Wang, J., Laskin, A., Shutthanandan, V., Zheng, J., Zhang, R., Gaffney, J., Marley, N. A., Paredes-Miranda, G., Arnott, W. P., Molina, L. T., Sosa, G., and Jimenez, J. L.: Mexico City aerosol analysis during MILAGRO using high resolution aerosol mass spectrometry at the urban supersite (T0) - Part 1: Fine particle composition and organic source apportionment, Atmos. Chem. Phys., 9, 66336653, doi:10.5194/acp-9-6633-2009, 2009.

Brook, R. D., Rajagopalan, S., Pope, C. A., III, Brook, J. R., Bhatnagar, A., Diez-Roux, A. V., Holguin, F., Hong, Y., Luepker, R. V., Mittleman, M. A., Peters, A., Siscovick, D., Smith Jr., S. C., Whitsel, L., and Kaufman, J. D.: Particulate matter air pollution and cardiovascular disease: an update to the scientific statement from the American Heart Association, Circulation, 121, 23312378, 2010.

Chase, R. E., Duszkiewicz, G. J., Richert, J. F.O., Lewis, D., Maricq, M. M., and Xu, N.: PM measurement artifact: Organic vapor deposition on different filter media, SAE, paper 2004-01-0967, 2004.

Cho, S., Makar, P. A., Lee, W. S., Herage, T., Liggio, J., Li, S. M., Wiens, B., and Graham, L.: Evaluation of a unified regional airquality modeling system (AURAMS) using PrAIRie2005 field study data: The effects of emissions data accuracy on particle sulphate predictions, Atmos. Environ., 43, 1864-1877, 2009.

DeCarlo, P. F., Kimmel, J. R., Trimborn, A., Northway, M. J., Jayne, J. T., Aiken, A. C., Gonin, M., Fuhrer, K., Horvath, T., Docherty, K. S., Worsnop, D. R., and Jimenez, J. L.: Field-deployable, high-resolution, time-of-flight aerosol mass spectrometer, Anal. Chem., 78, 8281-8289, 2006.

Dockery, D. W., Pope, C. A., Xu, X., Spengler, J. D., Ware, J. H., Fay, M. E., Ferris, B. G., and Speizer, F. E.: An association between air pollution and mortality in six US cities, N. Engl. J. Med., 329, 1753-1759, 1993.

European Commission, Communication on the application and future development of Community legislation concerning vehicle emissions from light-duty vehicles and access to repair and maintenance information (Euro 5 and 6) (http://eur-lex.europa.eu/LexUriServ/LexUriServ.do?uri= CELEX:52008XC0719(03):en:NOT), 2008.

Geller, M. D., Ntziachristos, L., Mamakos, A., Samaras, Z. Schmitz, D. A., Froines, J. R., and Sioutas, C.: Physicochemical and redox characteristics of particulate matter (PM) emitted from gasoline and diesel passenger cars, Atmos. Environ., 40, 6988-7004, 2006.

Graham, L.: Chemical characterization of emissions from advanced technology light-duty vehicles, Atmos. Environ., 39, 2385-2398, 2005.

Gong, S. L., Barrie, L. A., Blanchet, J.-P., von Salzen, K., Lohmann, U. Lesins, G., and Spacek, L.: Canadian aerosol module: A sizesegregated simulation of atmospheric aerosol processes for climate and air quality models 1 . module development, J. Geophys. Res. 108, AAC 3-1 AAC 3-16, 2003.

Grieshop, A. P., Miracolo, M. A., Donahue, N. M., and Robinson, A. L.: Constraining the volatility distribution and gas-particle partitioning of combustion aerosols using isothermal dilution and thermodenuder measurements, Environ. Sci. Technol., 43, 47504756, 2009.

Hallquist, M., Wenger, J. C., Baltensperger, U., Rudich, Y., Simpson, D., Claeys, M., Dommen, J., Donahue, N. M., George, C., Goldstein, A. H., Hamilton, J. F., Herrmann, H., Hoffmann, T., Iinuma, Y., Jang, M., Jenkin, M. E., Jimenez, J. L., Kiendler-Scharr, A., Maenhaut, W., McFiggans, G., Mentel, Th. F., Monod, A., Prvt, A. S. H., Seinfeld, J. H., Surratt, J. D., Szmigielski, R., and Wildt, J.: The formation, properties and impact of secondary organic aerosol: current and emerging issues, Atmos. Chem. Phys., 9, 5155-5236, doi:10.5194/acp-95155-2009, 2009.

Jacob, D. J. and Winner, D. A.: Effect of climate change on air quality, Atmos. Environ., 43, 51-63, 2009.

Khalek, I. A., Kittelson, D., and Brear, F.: The influence of dilution conditions on diesel exhaust particle size distribution measurements, SAE, paper 1999-01-1142, 1999

Kittelson, D. B.: Engines and nanoparticles: A review, J. Aerosol Sci., 29, 575-588, 1998 .

Kwon, S.-B., Lee, K.W., Saito, K., Shinozaki, O., and Seto, T.: Size-dependent volatility of diesel nanoparticles: Chassis dynamometer experiments, Environ. Sci. Technol., 37, 1794-1802. 2003.

Larson, S. M., Cass, G. R., Hussey, K. J., and Luce, F.: Verification of image processing based visibility models, Environ.Sci. Technol., 22, 629-637, doi:10.1021/es00171a003, 1988.

Liggio, J. and Li, S.-M.: Reversible and irreversible processing of biogenic olefins on acidic aerosols, Atmos. Chem. Phys., 8, 2039-2055, doi:10.5194/acp-8-2039-2008, 2008.

Liggio, J., Li, S.-M., and McLaren, R.: Heterogeneous reactions of glyoxal on particulate matter: identification of acetals and sulfate esters, Environ. Sci. Technol. 39, 1532-1541, 2005.

Liggio, J., Li, S.-M., Brook, J., and Mihele, C.: Direct polymerization of isoprene and $\alpha$-pinene on acidic aerosols, Geophys. Res. Lett., 34, L05814, doi:10.1029/2006GL028468, 2007.

Lipsky, E. M. and Robinson, A. L.: Effects of dilution on fine particle mass and partitioning of semivolatile organics in diesel exhaust and wood smoke, Environ. Sci. Technol., 40, 155-162, 2006.

Liu, P. S. K., Deng, R., Smith, K. A., Williams, L. R., Jayne, J. T., Canagaratna, M. R., Moore, K., Onasch, T. B., 
Worsnop, D. R., and Deshler, T.: Transmission efficiency of an aerodynamic focusing lens system: comparison of model calculations and laboratory measurements for the Aerodyne Aerosol Mass Spectrometer, Aerosol Sci. Technol., 41, 721-733, doi:10.1080/02786820701422278, 2007.

Maricq, M., Chase, R., Podsiadlik, D., and Vogt, R.: Vehicle exhaust particle size distributions: a comparison of tailpipe and dilution tunnel measurements, SAE, paper 1999-01-1461, 1999.

Mathis, U., Ristimäki, J., Mohr, M., Keskinen, J., Ntziachristos, L., Samaras, Z., and Mikkanen, P.: Sampling conditions for the measurement of nucleation mode particles in the exhaust of a diesel vehicle, Aerosol Sci. Technol., 38, 1149-1160, 2004.

Mathis, U., Mohr, M., and Forss, A.-M.: Comprehensive particle characterization of modern gasoline and diesel passenger cars at low ambient temperatures, Atmos. Environ., 39, 107-117, 2005.

Mohr, C., Huffman, J. A., Cubison, M. J., Aiken, A. C.,Docherty, K. S., Kimmel, J. R., Ulbrich, I. M., Hannigan, M., and Jimenez, J. L.: Characterization of primary organic aerosol emissions from meat cooking, trash burning, and motor vehicles with highresolution aerosol mass spectrometry and comparison with ambient and chamber observations, Environ. Sci. Technol., 43, 24432449, 2009.

Ng, N. L., Canagaratna, M. R., Jimenez, J. L., Zhang, Q., Ulbrich, I. M., Worsnop, D. R.: Real-time methods for estimating organic component mass concentrations from aerosol mass spectrometer data, Environ. Sci. Technol., 45, 910-916, 2011.

Onasch, T. B., Siefert, R. L., Brooks, S. D., Prenni, A. J., Murray, B., Wilson, M. A., and Tolbert, M. A.: Infrared spectroscopic study of the deliquescence and efflorescence of ammonium sulfate aerosol as a function of temperature, J. Geophys. Res., 104, 21,317-21,326, 1999.

Park, K. H., Cao, F., Kittelson, D. B., and McMurry, P. H.: Relationship between particle mass and mobility for diesel exhaust particles, Environ. Sci. Technol., 37, 577-583, 2003.

Pope CA, 3rd, Dockery DW. Health effects of fine particulate air pollution: lines that connect, J. Air Waste Manag. Assoc., 56, 709-742, 2006.

Prenni, A. J., DeMott, P. J., and Kreidenweis, S. M.: Water uptake of internally mixed particles containing ammonium sulfate and dicarboxylic acids, Atmos. Environ., 37, 4243-4251, 2003.

Robinson, A. L., Donahue, N. M., Shrivastava, M. K., Weitkamp, E. A., Sage, A. M., Grieshop, A. P., Lane, T. E., Pierce, J. R., and Pandis, S. P.: Rethinking organic aerosols: semivolatile emissions and photochemical aging, Science, 315, 1259, doi:10.1126/science.1133061, 2007.
Sakurai, J., Park K., McMurray, P. H., Zarling, D. D., Kittelson, D. B., and Ziemann, P. J.: Size-dependent mixing characteristics of volatile and nonvolatile components in diesel exhaust aerosols, Environ. Sci. Technol., 37, 5487-5495, 2003.

Schwarze, P. E., Orevik, J., Lag, M., Refsnes, M., Nafstad, P., Hetland, R. B., and Dybing, E.: Particulate matter properties and health effects: Consistency of epidemiological and toxicological studies, Hum Exp. Toxicol., 25, 559-579, 2006.

Seinfeld, J. H and Pandis, S. N.: Atmospheric Chemistry and Physics, John Wiley and Sons, New York, USA, 1326 pp., 1998.

Schauer, J. J., Kleeman, M. J., Cass, G. R., and Simoneit, B. R. T.: Measurement of emissions from air pollution sources. 5. $\mathrm{C}_{1}$ $\mathrm{C}_{32}$ organic compounds from gasoline-powered motor vehicles, Environ. Sci. Technol., 36, 1169-1180, 2002.

Shrivastava, M. K., Lipsky, E. M., Stanier, C. O., and Robinson, A. L.: Modeling semivolatile organic aerosol mass emissions from combustion systems, Environ. Sci. Technol., 40, 26712677, 2006.

Slowik, J. G., Vlasenko, A., McGuire, M., Evans, G. J., and Abbatt, J. P. D.: Simultaneous factor analysis of organic particle and gas mass spectra: AMS and PTR-MS measurements at an urban site, Atmos. Chem. Phys., 10, 1969-1988, doi:10.5194/acp-10-19692010, 2010.

Smyth, S. C., Jiang, W., Roth, H., Moran, M. D., Makar, P. A., Yang, F., Bouchet, V. S., and Landry, H.: A comparative performance evaluation of the AURAMS and CMAQ air-quality modelling systems, Atmos. Environ., 43, 1059-1070, 2009.

Stroud, C. A., Morneau, G., Makar, P. A., Moran, M. D., Gong, W., Pabla, B., and Zhang, J.: OH-reactivity of volatile organic compounds at urban and rural sites across Canada: Evaluation of air quality model predictions using speciated VOC measurements, Atmos. Environ., 42, 7746-7756, 2008.

US EPA, US Environmental Protection Agency: Emission factor documentation for AP-42, Technical Support Division, Office of Air Quality Planning and Standards, US Environmental Protection Agency, Research Triangle Park, NC, 1993.

US EPA, US Environmental Protection Agency: Emission factor documentation for AP-42 Section 1.10 Residential Wood Stoves, US EPA, Washington DC, USA, 1996. 